\title{
GEOSPATIAL APPROACH TO CATEGORIZE AND COMPARE THE AGRO- CLIMATOLOGICAL DROUGHTS OVER MARATHWADA REGION OF MAHARASHTRA, INDIA
}

\author{
Sneha Kulkarni ${ }^{1, *}$, Shirishkumar Gedam ${ }^{1}$ \\ ${ }^{1}$ CSRE, Indian Institute of Technology- Bombay, Powai, Mumbai, India 400076 - (snehakulkarni, shirish)@iitb.ac.in
}

Commission V, SS: Disaster Monitoring, Damage Assessment and Risk Reduction

KEY WORDS: Drought, Meteorological Drought, MODIS, SPI, TRMM, Vegetation Drought, VCI

\begin{abstract}
:
The present study mainly focuses on the comparison and quantification of meteorological droughts with agricultural droughts to understand their relationship to the occurrences and intensities of droughts. This study is based on analysis of the changing agroclimatological drought conditions from the year 2001 to 2017, over the districts of Marathwada, which are known to be the most drought-prone regions of the Maharashtra, India. To quantify the drought severity, Standardized Precipitation Index (SPI) from TRMM and Vegetation Condition Index (VCI) from MODIS datasets have been derived and compared. This study indicated that the years 2002, 2009, 2014 and 2015 were the most severe drought periods over Marathwada. Parts of Nanded, Aurangabad and Latur districts were the highest drought-affected areas from last 17 years, where the frequency of agricultural drought incidence was more than eight years. Over the districts of Hingoli and Parbhani, decreasing rainfall trends plus highly negative values of SPI $(\leq-$ 1.5 ) in the month of July shows a major concern for agricultural activities. Positive correlation-ship (41\%) was noticed between SPI and VCI during the study period, but it was not statistically significant. In the year 2015, which was one of the intense drought years, it is noted that the agricultural drought was the most influencing drought type covering about 53\% of the affected area. This study thus can help in identification of drought types and their intensities with spatial extent through an area specific interdisciplinary approach which in turn will help to develop region-specific drought mitigation and management strategies.
\end{abstract}

\section{INTRODUCTION}

In Indian scenarios, due to the interdependent nature of agroclimatological parameters, assessment and quantification of droughts have become a complex problem. To overcome this, comparison and linkage of different drought types and indices is a key way to achieve the highest accuracy in drought monitoring (Zhang et al., 2017). Many studies (Kulkarni et al., 2017), (Mallya et al., 2015), (Mishra et al., 2014), (Patel et al., 2008) and (Bhuiyan et al., 2006) etc. have attempted drought monitoring for various parts of India using single in-situ agroclimatological and remotely sensed parameters. But there is a lack in the interdisciplinary relationship-based approach, which considers multiple drought types together for achieving the better accuracy in drought monitoring. Therefore, to overcome this issue, this study mainly aims to relate the Meteorological Drought Index and Vegetation Drought Index. From last many decades, Indian Meteorological Department (IMD) continually monitoring meteorological drought conditions on the basis of rainfall variations (Pai et al., 2010)where they have noticed mixed nature of dry and wet spells. The SPI related research (Pai et al., 2011) noticed the year 1971-72, 1982,1984, 1987, 2002 and 2009 as extreme drought years. In continuation, various researchers (Niranjan Kumar et al., 2013) and (Naresh Kumar et al., 2012) have also observed subdivision based agroclimatological drought vagaries, which resulted in the increasing number of severe drought conditions. In the state of Maharashtra, a subdivision of Marathwada is one of the most drought-affected regions from past. It is recently known for its brutal drought condition and thousands of farmer's suicide in the year 2014- 2015(Kulkarni et al., 2016) which was adversely affected the overall socio-economical condition of that area. Hence to overcome this issue, in the present study, we have monitored and analyzed the drought conditions of Marathwada, in which one of the major concerns was 2015 severe drought over this region.

\subsection{Study Area}

The present study was carried out for the eight districts of Marathwada, India named as, Aurangabad, Jalna, Beed, Parbhani, Hingoli, Osmanabad, Latur and Nanded. This area falls under the tropical semi-arid zone with the latitudinal expand of $17^{\circ} 35^{\prime}$ North to $20^{\circ} 41^{\prime}$ North and longitudinal extent is $74^{0} 40^{\prime}$ East to $78^{0} 16^{\prime}$ East (Figure 1). The major area of Marathwada lies under the rain shadow zone of Western Ghats. This area receives, $600 \mathrm{~mm}$ to $800 \mathrm{~mm}$ average rainfall in which more than $80 \%$ of annual rainfall is dependent on the south-west monsoon.

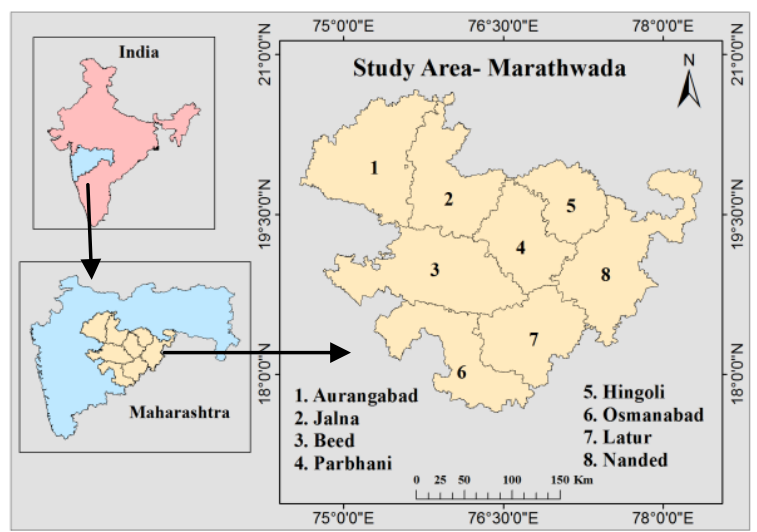

Figure 1. Study Area 


\section{METHODOLOGY}

The approach involves calculating the VCI, SPI and performing the geospatial analysis to derive a composite index utilizing NDVI and precipitation data.

\subsection{Data}

Tropical Rainfall Measurement Mission (TRMM) and Terra Moderate- Resolution Imaging Spectroradiometer (MODIS) were the two satellite-based datasets have been used for this study. Monthly $0.25 * 0.25$ degree merged (3B43) TRMM dataset were obtained from GES DISC data provider, NASA for the period of 2001 to 2017. Station based monthly rainfall dataset (1951 to 2016) was taken from the Indian Meteorological Department (IMD). This long-term station based dataset was used to carry out and verify the SPI analysis. The Normalized Difference Vegetation Index (NDVI) (level-3MOD13A2) dataset with $1 \mathrm{~km} * 1 \mathrm{~km}$ resolution (MODIS) was acquired from the Earth Observing System (EOS) of NASA. 16 days composite NDVI data were converted into a monthly scale and analyzed using remote sensing software's.

\subsection{Techniques and Methods}

Statistical analysis and satellite-based image analysis were the two main techniques have been used for this study. For the comparative analysis of indices, VCI datasets were resampled in $0.25 * 0.25$ degree resolution.

Two widely used drought indices; SPI (meteorological drough indicator) and VCI (Vegetation drought indicator) were comparatively studied in this study. In the preliminary stage, both the datasets (NDVI and rainfall) were spatially and temporary (2001 to 2017) analyzed and results were generated for VCI and SPI. As the second part of this study, 2015 was selected as a representative and a recent severe drought year, which has used in the further analysis of area-specific drought type identification.

2.2.1 SPI: Standardized Precipitation Index (SPI) (Mckee et al., 1993) is one of the most powerful and popular meteorological indexes used to analyze the wet and dry periods (Ren et al., 2008). It can be calculated on different temporal scales (1, 3, 6, 9, 12 months). The SPI is defined as,

$$
\mathrm{SPI}=\frac{X-X m}{\sigma}
$$

Where,

$\mathrm{X}=$ Precipitation for the station

$\mathrm{Xm}=$ Mean Precipitation

$\sigma=$ Slandered Deviation

The negative values of SPI represent the moderate to extreme drought conditions whereas positive values are the indicator of wet conditions (Table 1).

2.2.2 VCI: Vegetation Condition Index (Kogan, 1990) is a pixel-based normalization of NDVI. VCI represents the area specific vegetation status. The higher values of VCI are linked with the higher amount of vegetation cover(Bhuiyan, 2004) and (Quiring and Ganesh, 2010). The results for VCI can be computed by following formula,

$$
\mathrm{VCI}=\frac{(\text { NDVI-NDVImin })}{(\text { NDVImax }- \text { NDVImin })} * 100
$$

Where, The NDVI values are based on grid cell value. The VCI ranges from 0 to 100 in which near o values indicates the extreme drought condition whereas values closer to 100 represents the wet vegetation state (Table 1). The near 50 values of VCI are the sign of a slightly good condition of agriculture which is mainly based on local ecosystem productivity.

\begin{tabular}{lcc}
\hline $\begin{array}{l}\text { Drought } \\
\text { Category }\end{array}$ & SPI Range & $\begin{array}{c}\text { VCI Range } \\
(\%)\end{array}$ \\
\hline $\begin{array}{l}\text { Extreme } \\
\text { Drought }\end{array}$ & SPI $\leq-2$ & VCI $<10$ \\
$\begin{array}{l}\text { Severe } \\
\text { Drought }\end{array}$ & $-2<$ SPI $\leq-1.5$ & $10 \leq \mathrm{VCI} \leq 20$ \\
$\begin{array}{l}\text { Moderate } \\
\text { Drought } \\
\text { No drought }\end{array}$ & $-1.5<$ SPI $\leq-1$ & $20<\mathrm{VCI}<35$ \\
\hline
\end{tabular}

Table 1. Drought types, categories and its ranges

\section{RESULTS AND DISCUSSIONS}

\subsection{Droughts and Severities (SPI Based)}

Figure 2 shows the result for time series analysis of SPI values. SPI is helpful for short as well as long duration rainfall analysis (Ren et al., 2008). As a long-term scale, from the year 1951 to 2016, mixed nature of dry and wet spells was observed over most of the districts of the study area in which nearly $50 \%$ years were under moderate to extreme drought conditions. On a shorter scale, 1984 to 1988 and 2000 to 2004 were noticed as a major dry period over the Marathwada. In the decade of 2000 to 2010 , the maximum number of dry years was examined, in which 2002 and 2009 were the severe drought years. Among eight districts, Jalna and Latur were continually under less amount of precipitation and experienced three extreme drought years (SPI values were -2.82 and -2.56 respectively). Over the year 2014 and 2015, almost all the districts examined SPI values less than -1.2 , among which Osmanabad (-1.75), Beed (1.68), Latur (-1.56) were under extreme drought situation. As the SPI is a direct indicator of rainfall deficiency, it helped to draw the temporal distribution pattern with the dry period frequencies of precipitation.

\subsection{Droughts and Severities (VCI Based)}

In this study, for analyzing the spatio-temporal distribution of vegetation based drought cases, VCI was computed from the period 2001 to 2017. Study area as the whole, VCI helped to differentiate between drought and non-drought years (Figure 3) 2006, 2010, 2013, and 2016 were noticed as wet years, where the VCI values for most of the areas were more than 50 . Aurangabad and Osmanabad were the two districts which experience the maximum number of wet periods. This study identifies the year 2002, 2008, 2009, 2014 and 2015 as an intense drought years from last two decades, which supports the results by (Mallya et al., 2015) and (Niranjan Kumar et al., 2013 ) etc. This study majorly highlighted the drought occurrences over the consecutive years. 2002-2003, 2008-2009 and 2014-2015 were the noticeable adjoin years with maximum drought severities. 


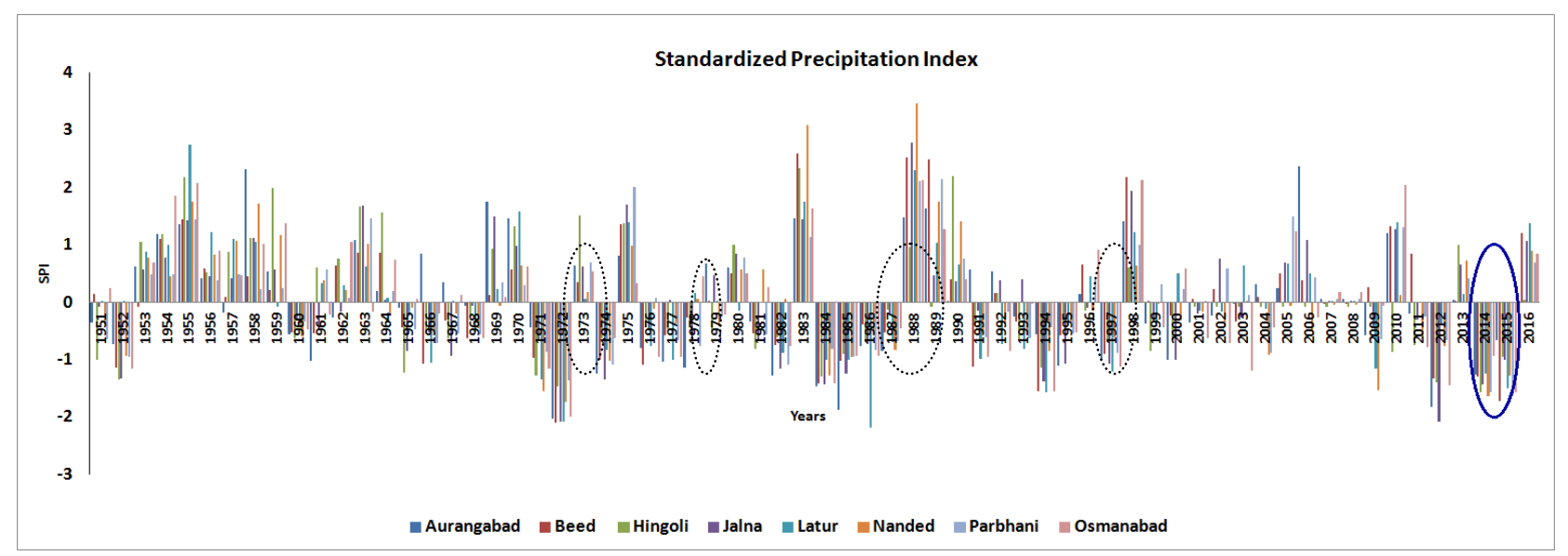

Figure 2. Variations in SPI from the year 1951 to 2016

In the extreme drought years $(2002,2005)$ more than 42000 $\mathrm{km}^{2}$ area of Marathwada was under the severe to extreme drought condition. In the month of October, Aurangabad, Nanded, Latur and Hingoli were the districts which affected greatly and noticed less than 25 values for VCI. This observed dryness over the month of October was continued in rest of the post-monsoon season making that year as the worst year for agricultural activities. The eastern and northeastern part of Marathwada were highly frequented by severe to extreme drought scenarios and also noticed lowest values of VCI for more than 14 years in the month of November and December. With compare to September, vegetation drought intensity is significantly increasing in November followed by the month of December. Due to the low number of extreme droughts, the south and western parts of Marathwada (Osmanabad and Beed) were marked as less vulnerable areas to agricultural drought.

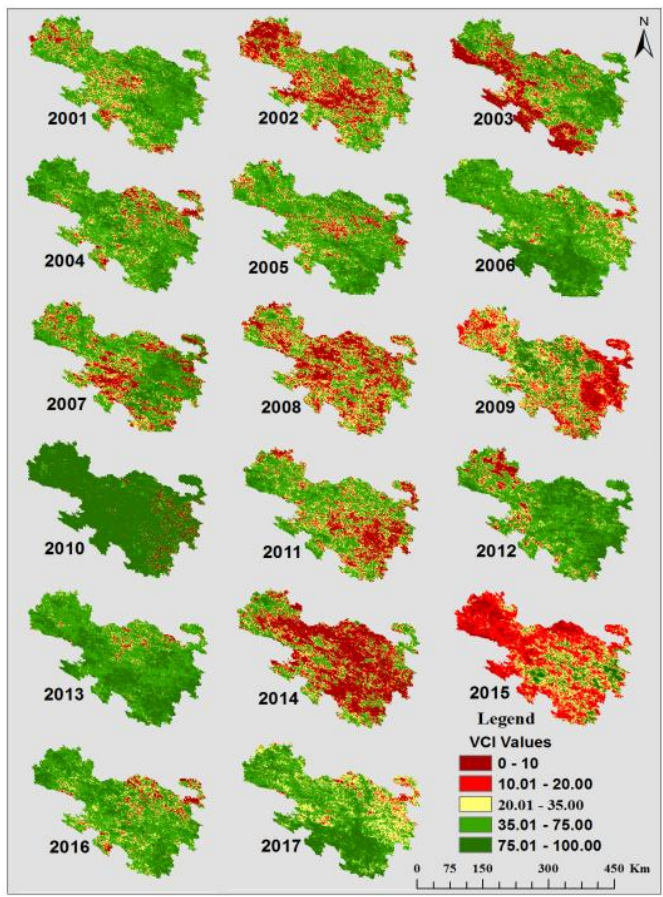

Figure 3. Spatio-temporal variations in VCI over the month of October

In general, from last 17 years, study area as a whole, moderately affected area was more with compare to the severe or extreme vegetation droughts.

\subsection{Drought frequencies and severities}

3.3.1 VCI (Figure 4) (Table 2): To match the spatial scale of TRRM with VCI, corresponding VCI datasets were resampled as $0.25^{*} 0.25$ degree and analyzed further to identify the drought frequencies. From last 17 years, the post-monsoon season as a whole, seven times moderate to extreme drought condition was noticed over the $19 \%$ of the study area. Nanded, Latur and Parbhani were the districts where the high numbers of drought frequencies were noticed. Six times, $15 \%$ of the area experiences the vegetation deficiency followed by five times involvement of $18 \%$ of the region under moderate to severe dryness in the overall postmonsoon season. In the month of October, $15 \%$ area including central part of Beed and Parbhani and a major part of Osmanabad experiences drought for more than 8 times.

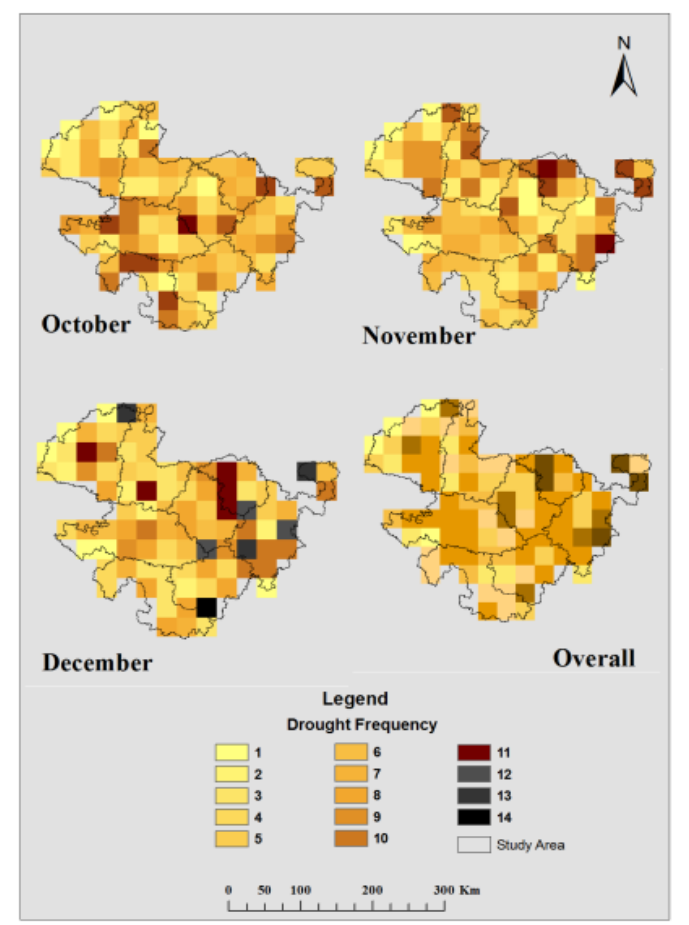

Figure 4. Month-wise number of years under vegetation drought condition from 2001- 2017 
The monthly drought analysis using VCI also indicates that the November month was the moderate period where $10 \%$ area of the Marathwada undergone drought cases for 7 to 8 times from the past 17 years. The total number of drought occurrences and affected area due to its brutality were highest in the month of December. Most of the moderate and severe drought areas from the month of November and December were followed further and became significantly harsh in the month of December. 18 to $20 \%$ of the study area, mainly, parts of Parbhani, Hingoli, Beed and Latur experiences the drought cases for more than 9 times. This high frequency and rising severities of VCI based drought enhance the agricultural and socio-economical problems to a greater extent.

\begin{tabular}{ccccc}
\hline $\begin{array}{l}\text { Drought } \\
\text { occurrences } \\
\text { Count(2001 }\end{array}$ & October & $\begin{array}{c}\text { Affected Area (\%) } \\
\text { November }\end{array}$ & December & Overall \\
-2017) & & & & \\
\hline 01 & 07 & 09 & 07 & 04 \\
02 & 10 & 12 & 05 & 08 \\
03 & 11 & 14 & 12 & 13 \\
04 & 12 & 10 & 12 & 10 \\
05 & 19 & 18 & 09 & 18 \\
06 & 15 & 8 & 07 & 15 \\
07 & 10 & 10 & 10 & 19 \\
08 & 08 & 10 & 12 & 08 \\
09 & 02 & 04 & 04 & 05 \\
10 & 05 & 03 & 09 & \\
11 & 01 & 02 & 05 & \\
12 & & & 03 & \\
13 & & & 03 & \\
14 & & & 01 & \\
\hline
\end{tabular}

Table 2. VCI based drought affected area (\%) and its areaspecific frequencies

3.3.2 SPI (Figure 5): Wide spatio-temporal spread is observed as the main characteristics of SPI for the study area. Monsoon as a whole, $18 \%$ of the study area experiences severe or extreme drought conditions for 3 from the time span of 17 years. Parbhani and Latur were the districts, where the high frequency and increasing severity were noticed. In continuation, $32 \%$ region of the Marathwada has examined the drought extremes for 2 years among 17 years.

From 2001 to 2017, in the month of June for 3 years, 58\% of the area has observed brutal dryness. The maximum dry conditions were over the Latur and Parbhani districts followed by Beed and Aurangabad. In the later months (July, August, and September) 40 to $55 \%$ area was under a drought scenario which was repeated 2 times, in the 17 years time duration. Like the month of June, parts of Parbhani, Latur and Beed were the most drought-affected regions. In the month of July, 15\% region was under severe and extream drought conditions for 3 years, which shows the major concern for agricultural activities (it is the sowing period in the study area) (Ministry of Agriculture and Farmers Welfare, 2017).

\subsection{SPI and VCI- Monthly Mean Relationship}

In this study, the linear regression method has been used to understand the correlation between meteorological and Vegetation Index. This analysis suggested $41 \%$ of non- significant positive relationship within SPI and VCI. This result indicates the primary control of SPI over the VCI. But as the trend is not statistically significant and the correlation is

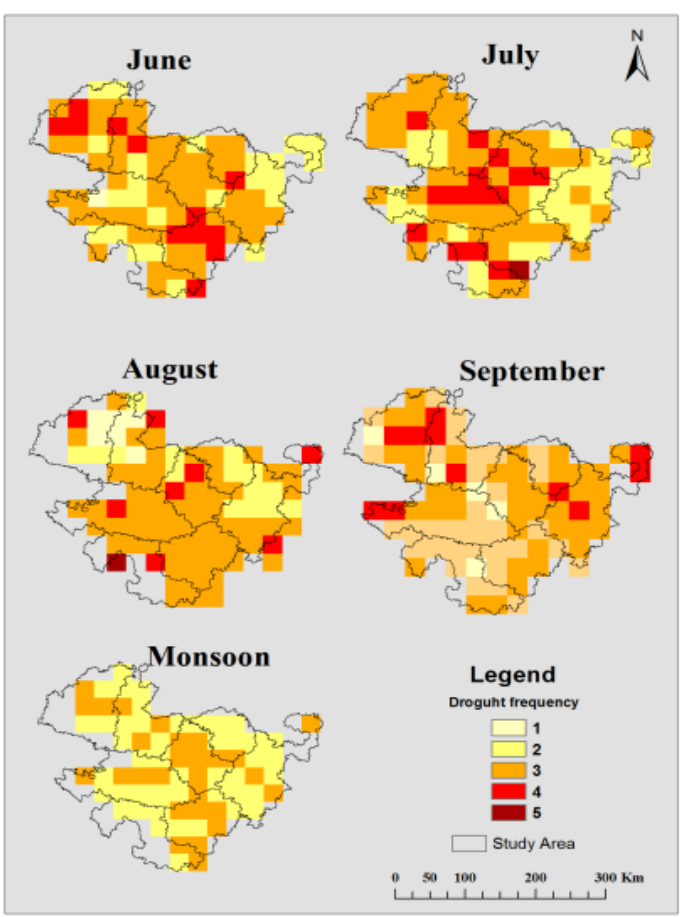

Figure 5. Month-wise number of years under meteorological drought condition from 2001 to 2017

less than $50 \%$ (Figure 6), we can say that more than precipitation, there may be some other factors which are responsible for vegetation droughts. Therefore, one should not consider only SPI as a drought indicator for different agroclimatological studies.

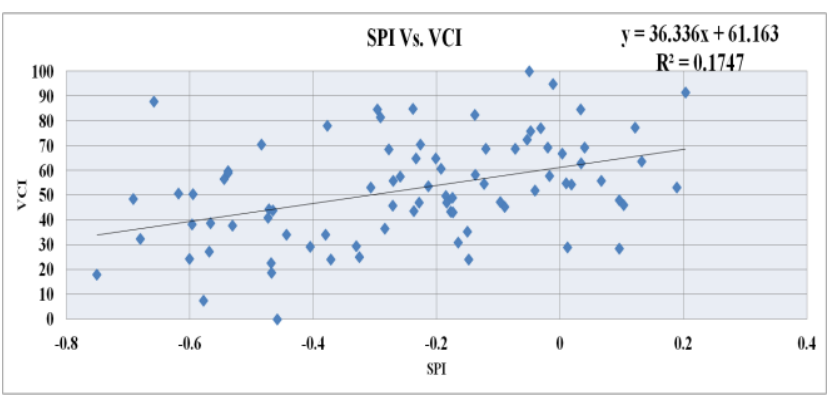

Figure 6. Correlation between Meteorological and Vegetation Drought Index

\subsection{Area Specific Drought Categorisation}

In the past, many studies have given the singular view of drought assessment. Among them, various cases were lacking in the interlink-edge of agricultural and meteorological indices which results in poor drought management and implementation of wrong methodologies to overcome on the drought-related issues. Therefore, the present study shades light on the areaspecific drought categorization. The above-mentioned results showed that the year 2015 was one of the most severe drought years and July month was the most crucial month, hence, the year 2015 is considered for the further analysis. In this part of the study, the yearly average of VCI and annual TRMM rainfall 
data were considered. For the comparison, VCI data were resampled at TRMM scale $(0.25 * 0.25$ scale $)$.

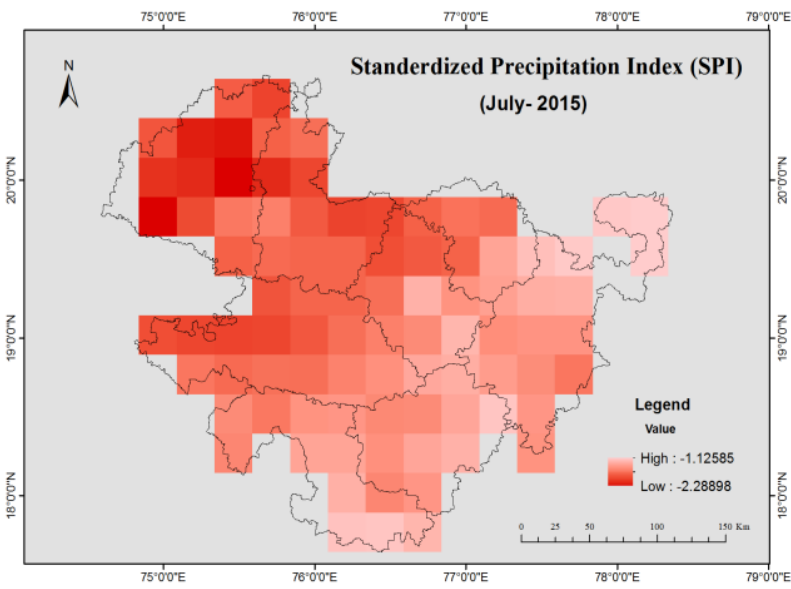

Figure 7. Spatial distribution of Meteorological Drought

(2015)

Figure 7 shows the spatial distribution of Meteorological drought (SPI) over the Marathwada. The negative values of SPI vary from -1.12 to -2.28 which represent the moderate to extreme drought condition over the whole study area. Aurangabad was the district with highest negative values of SPI followed by Beed and Jalna. Figure 8 represents the annual vegetation condition of 2015 over the Marathwada where 62\% of the area was under severe to extreme drought condition. Nanded, Aurangabad, Jalna and Parbhani were the districts with iii. highest vegetation drought severity.

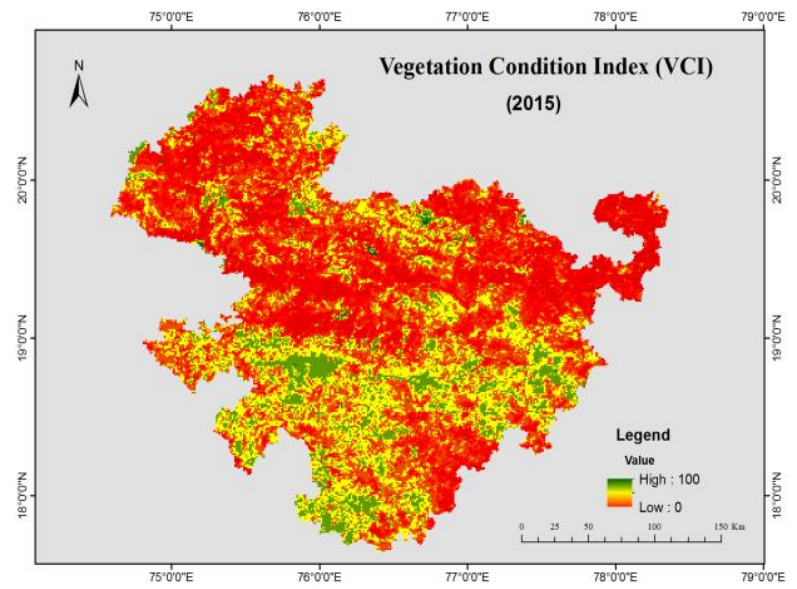

Figure 8. Spatial Distribution of Vegetation Drought (2015)

After the separate analysis of both the indices, they were normalized for the further investigation. Both the data were converted (normalized) in the range of 0 to 1 and stacked before applying the counting method. Final results (Figure 9) were obtained by processing both the images simultaneously. The result represents that the maximum amount of severe drought was due to the adverse vegetation condition which affected greatly on various parts of the study area. 53\% area of Marathwada was under intense vegetation-drought condition; whereas $40 \%$ area was influenced more due to the meteorological drought. Only $7 \%$ area was experienced the equal impact of VCI and SPI.

This result conveys that, there are high chances of occurrences of multiple drought types at same spatio-temporal scale, therefore researcher and common people must study and focus on the interdisciplinary nature and area wise variations of droughts, for the better understanding of the droughts and its impacts.

\section{CONCLUSIONS}

In the Marathwada region, rainfed agriculture is one of the major forms of agriculture which contributes more than $28 \%$ of the GDP and hence depends largely on the vagaries of agroclimatological droughts. Thus, understanding of spatiotemporal, agro-climatological variability assumes more importance as the driving factors of the socio-economical development of the area (Act-Indian economic ministry, 2016). Several earlier studies did not consider the local Geospatial variability of causative factors and hence the present study can be the major step towards comparative analysis and implementation of two different types of indices together. From the present studies, it can be concluded that,

i. The Meteorological Drought Index (SPI) and Vegetation Drought Index (VCI) are good indicators of spatiotemporal variations of droughts over the districts of Marathwada, but they are statistically not correlated. Therefore, there is need of consideration of both while analyzing the agro-climatological drought conditions.

ii. From last two decades, high intensity of droughts was noticed over the adjoining year's ex. 2002-2003, 20082009 and 2014-2015.

As per VCI analysis, Nanded, Parbhani and Latur were the most affected regions due to vegetation drought cases. From last 17 years, the post-monsoon season as a whole, seven times moderate to extreme drought condition was noticed over the $19 \%$ of the study area. This high frequency of severe to extreme drought is a major concern towards agriculture.

iv. As per the SPI analysis, Parbhani and Latur examined the highest drought severities. Monsoon season as a whole, 18 $\%$ of the study area experiences severe or extreme drought conditions for three times, in the time span of 17 years.

V. The year 2015 was one of the most drought-affected years from last two decades, in which 53\% of the study area was under vegetation based drought while $40 \%$ area followed the meteorological drought conditions.

\section{ACKNOWLEDGMENT}

We are grateful to the Indian meteorological department (IMD); Ministry of Earth Sciences for providing the station based rainfall data. 


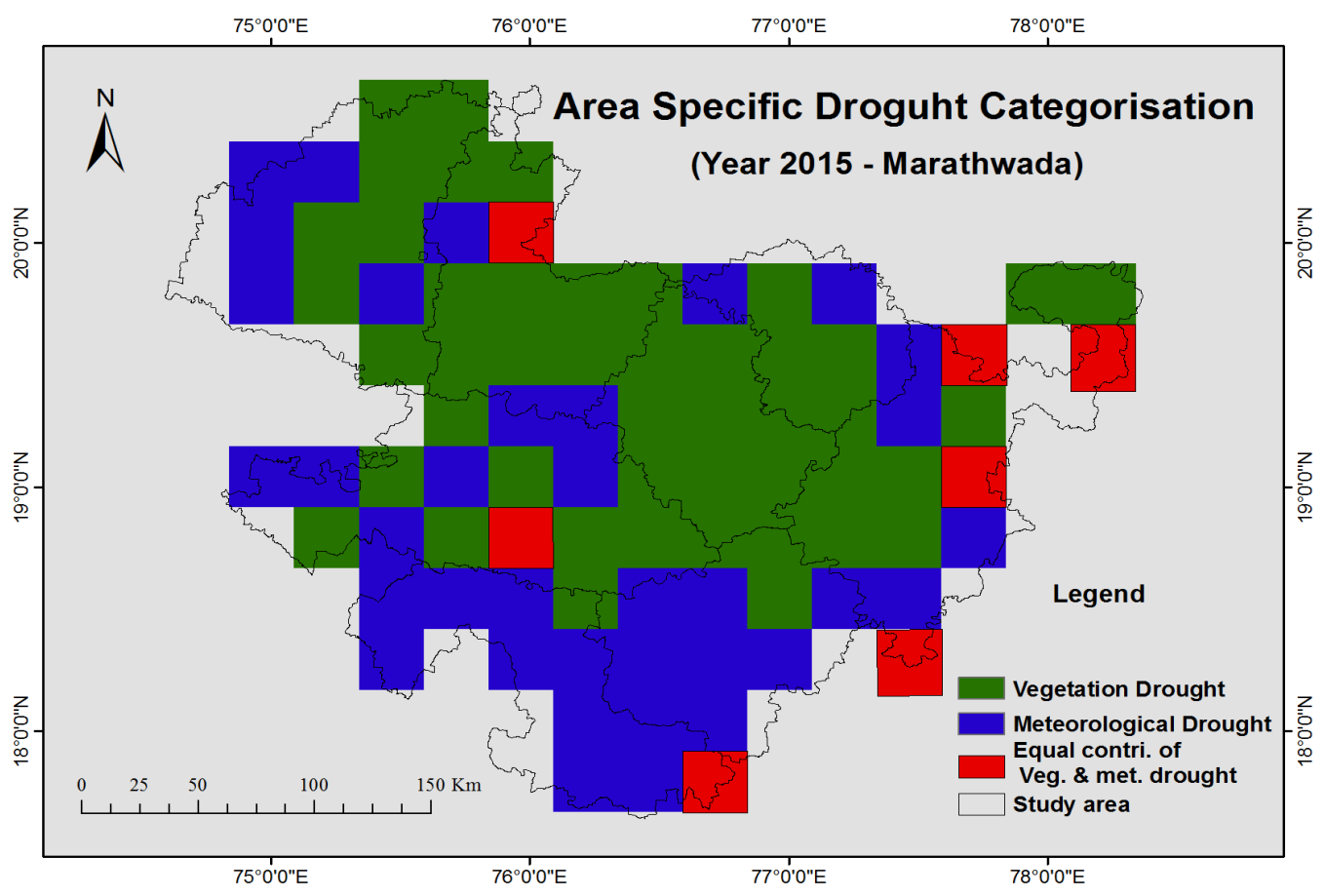

Figure 9. Area-specific categorization of Agro-climatological drought (2015)

\section{REFERENCES}

Act, B. M., 2016. Mid-Year Indian Economic analysis contents.

Bhuiyan, C., 2004. Various drought indices for monitoring drought condition in Aravalli terrain of India. ISPRS Int. J. Geo-Information 6.

Bhuiyan, C., Singh, R.P., Kogan, F.N., 2006. Monitoring drought dynamics in the Aravalli region (India) using different indices based on ground and remote sensing data. Int. J. Appl. Earth Obs. Geoinf. 8, 289-302. https://doi.org/10.1016/j.jag.2006.03.002

Kogan, F.N., 1990. Remote sensing of weather impacts on vegetation in non-homogeneous areas. Int. J. Remote Sens. 11, 1405-1419. https://doi.org/10.1080/01431169008955102

Kulkarni, A., Gadgil, S., Patwardhan, S., 2016. Monsoon variability, the 2015 Marathwada drought and rainfed agriculture. Curr. Sci. 111, 1182-1193. https://doi.org/10.18520/cs/v111/i7/1182-1193

Kulkarni, S., Gedam, S., Dhorde, A., 2017. Assessment of impacts of agro-climatological droughts over Marathwada, India, using remote sensing technologies. 38th Asian Conf. Remote Sens. - Sp. Appl. Touching Hum. Lives, ACRS 2017 2017-Octob.

Mallya, G., Mishra, V., Niyogi, D., Tripathi, S., Govindaraju, R.S., 2015. Trends and variability of droughts over the
Indian monsoon region. Weather Clim. Extrem. 12, 43-68. https://doi.org/10.1016/j.wace.2016.01.002

Mckee, T.B., Doesken, N.J., Kleist, J., 1993. The relationship of drought frequency and duration to time scales. AMS 8th Conf. Appl. Climatol. 179-184. https://doi.org/citeulikearticle-id:10490403

Ministry of Agriculture and Farmers Welfare, 2017. Agricultural Statistics at a Glance 2016 1-519.

Mishra, V., Shah, R., Thrasher, B., 2014. Soil Moisture Droughts under the Retrospective and Projected Climate in India*. J. Hydrometeorol. 15, 2267-2292. https://doi.org/10.1175/JHM-D-13-0177.1

Naresh Kumar, M., Murthy, C.S., Sesha Sai, M.V.R., Roy, P.S., 2012. Spatiotemporal analysis of meteorological drought variability in the Indian region using standardized precipitation index. Meteorol. Appl. 19, 256-264. https://doi.org/10.1002/met.277

Niranjan Kumar, K., Rajeevan, M., Pai, D.S., Srivastava, A.K., Preethi, B., 2013. On the observed variability of monsoon droughts over India. Weather Clim. Extrem. 1, 4250. https://doi.org/10.1016/j.wace.2013.07.006

Pai, D.S., Sridhar, L., Guhathakurta, P., Hatwar, H.R., 2011. District-wide drought climatology of the southwest monsoon season over India based on standardized precipitation index (SPI). Nat. Hazards 59, 1797-1813. https://doi.org/10.1007/s11069-011-9867-8

Pai, D.S., Sridhar, L., Guhathakurta, P., Hatwar, H.R., 2010. The Southwest Monsoon Season Precipitation Index ( SPI ) 
District-wise Drought Climatology Of The Southwest Monsoon Season over India Based on Standardized Precipitation Index ( SPI ).

Patel, N.R., Anapashsha, R., Kumar, S., Saha, S.K., Dadhwal, V.K., 2008. Assessing potential of MODIS derived temperature/vegetation condition index (TVDI) to infer soil moisture status. Int. J. Remote Sens. 30, 23-39. https://doi.org/10.1080/01431160802108497

Quiring, S.M., Ganesh, S., 2010. Evaluating the utility of the Vegetation Condition Index (VCI) for monitoring meteorological drought in Texas. Agric. For. Meteorol. 150, 330-339. https://doi.org/10.1016/j.agrformet.2009.11.015

Ren, G., Zhou, Y., Chu, Z., Zhou, J., Zhang, A., Guo, J., Liu, X., 2008. SPI user guide. J. Clim. 21, 1333-1348. https://doi.org/10.1175/2007JCLI1348.1

Zhang, X., Obringer, R., Wei, C., Chen, N., Niyogi, D., 2017. Droughts in India from 1981 to 2013 and Implications to Wheat Production. Sci. Rep. 7, 1-12. https://doi.org/10.1038/srep44552 